\title{
Total Quality Management Practice in Croatian Language Service Provider Companies
}

\author{
Sanja Seljan \\ University of Zagreb, Faculty of Humanities and Social Sciences, Croatia
}

\section{Abstract}

The aim of this paper is to perform analysis of existing practice of Quality Management (QM) and Total Quality Management (TQM) principles in Croatian Language Service Provider (LSP) companies in order to analyse the gap and suggest recommendations. In this case study, twelve SME Croatian LSP companies are analysed by number of employees, existing and missing workplaces, focused business market, offices, Quality Certificate ISO 9001:2015 (2015) and membership in professional organizations. The existing practice in LSP Croatian companies are analysed through 10 TQM (total quality management) principles using self-evaluation assessment.

Keywords: Quality Management (QM), Total Quality Management (TMQ), Language Service Provider (LSP), Croatia, micro and small companies, SMEs JEL classification: $\mathrm{O} 32, \mathrm{O} 33$

\section{Introduction}

A new industrial revolution, namely Industry 4.0 plays an important role in digital transformation, also in micro and small companies. Transformations happen on all stages of the production system, with the main aim to augment efficiency and productivity, at production, organizational and management levels.

The main aim is to increase selling power and competitiveness by introducing changes in business processes, through connected services and use of ICT, datadriven decision making and through interdependence with customers who gained the central role. Micro and small organizations are recognized as important business driver in Europe for job-creation, innovation and economy development, who slowly adopt total quality management (TQM) implementation. Small organizations are often suppliers of larger organizations, depending directly on them, or often cooperate with smaller number of customers. Hansson (2003) notices than small organizations can benefit from an implementation of TQM. In such organizations, manager is usually the owner of the company, often experiencing lack or resources (staff, software, and training) and having difficulties in obtaining financial support for additional changes or business innovations.

According to European Union (2003), SME (small and medium-sized) represent 99\% of all businesses in EU. Micro companies employ less than 10 employees, small companies less than 50, and medium companies less than 250 employees. Although these are not the only criteria to take into account, for the purpose of this pilot study, LSP companies are divided according to the number of employees.

Changes of digital transformation apply to Language Service Provider (LSP) companies, which experience shits at the production level, organization level, management and business process level. Translation process has become an issue 
more at corporate level, often performed as project-based task, rather than individual task, asking for flexible, adaptive and innovative environment.

LSP companies comprise more general service organization, offering more than just translation. They perform also project management for clients, desktop publishing (DTP), software globalization, and transcreation in multilingual projects, localization (L1On), internationalization (118n), globalization (G11n), including marketing, website translation and localization, including also technologies of machine translation (MT), computer-assisted translation.

LSP companies have faced with growing need for information access through translation and localization projects (e.g. various documentation in multitude of languages, web sites, promotional materials), communication in business environment (e.g. official documentation in multinational companies, documentation for foreign markets, manuals, records), need for translation of documentation of various devices and mobile applications (e.g. medical devices), etc. This situation also applies to Croatia, which as EU member, aims to answer the need for information access at all official EU languages, and to use ICT in the translation and localization process (Seljan et al., 2006). In this situation, new forms of management are required in the context of organizational, technological changes, increased specialization, shortened product cycle, increasingly sophisticated customers and complexity of the process.

Up to date researches are conducted for larger institutions, for more developed countries or with fragmented purposes, but none for developing countries or for SME companies. The aim of this paper is to perform analysis of existing practices of Quality Management (QM) and Total Quality Management (TQM) principles in Croatian Language Service Provider (LSP) companies in order to analyse the gap and suggest recommendations for the TQM process. In this case study, twelve SME Croatian LSP companies are analysed, by aligning selected TQM principles with existing practice through self-evaluation assessment.

\section{Related work}

There are a few researches on QM and TQM in LSP companies, but only for larger institutions, for more developed countries, for large international multilingual LSP companies or for fragmented purpose. There are no researches for developing countries or for micro and small LSP companies, which face challenges in competitive global environment and increasingly demanding customers.

Quality management (QM) was elaborated for the EU institutions and bodies, especially in the Directorate General for Translation (DGT) of the European Commission by (Svoboda et al., 2017; Hansson, 2003), then in several materials related to quality management in large European companies, in the research relating to TQM for UAE translation company (Alhashmi, 2016) and in the research relating to the analysis of efficiency of translation quality assurance tools (Gural et al., 2014; Makoushina, 2007). Researches related to QM in the Croatian environment were conducted for QA of terminology in a translation quality management system (QMS) in business environment (Seljan, in print), related to interdisciplinary curriculum changes (Seljan, 2011), or in game localization (Seljan et al., 2017) which are fragmented for the specific domain or oriented to analysis of tools and quality assurance of text (Kučiš et al., 2009).

Directorate General for Translation (DGT) of the European Commission (2009) has published a Programme for Quality Management in Translation - 22 Actions in order to assure the quality before, during and after the translation process in order to improve service quality, cost-effectiveness, transparency and traceability and to 
obtain more efficiency through integrative holistic approach. This program is closely related to Total Quality Management (TQM) exercise launched in DGT in 2007 with an idea to build Quality Management System (QMS) in DGT.

Quality as a concept appeared in the 20th century, and by industrial revolution and mass production, QC was used to ensure the quality of the final product. About 30 years later, QA was developed from the idea that it should start from the beginning of the process (Seljan et al., 2017). In the 80s, the concept of the Total Quality Management (TQM) appeared, with the idea to coordinate and assure all processes in the company, including constant improvement, customer focus and employee engagement.

Quality Management (QM) QM aims to meet standards and specifications through quality control, by planning on how to achieve results compatible with specifications through quality assurance, and to improve services through corrective feedback through quality improvement.

In LSP companies, QM consists of Quality assurance (QA), Quality control (QC) and Quality verification (QV). Quality control (QC) represents the most basic level of quality management, including verification, testing or checking a product/service to detect and correct any error, usually performed at the end of the process, mainly product-oriented and lacking to improve the quality.

Quality assurance (QA) is focused on activities of planning and documenting (steps, rules, activities, procedures) in order to prevent errors and to achieve the quality, usually performed at the beginning of the process, quality-oriented.

Quality verification (QV) includes activities of evaluation in order to provide feedback to the system with the purpose of constant improvement. QA and QC are often interchanged, although closely related.

Hoyle (1998) indicates that quality control (QC) is based on: Plan - Do - Check Re(Act), called PDCA model or Deming Cycle, originally founded by Shewhart in 1939, with phases of specification, production and inspection, and then created and modified by Deming (by W. Edwards Deming, considered by many as the "father of modern quality control"). Deming Cycle includes control function for monitoring the quality changes and improvements in the organization, which can be used to asses and improve the proper work, at all management levels (management board for business processes, middle management for sub processes as results of primary processes), through organizational and operational aspects..

Figure 1

PDCA Model or Deming Cycle

Improvement via PDCA Cycle

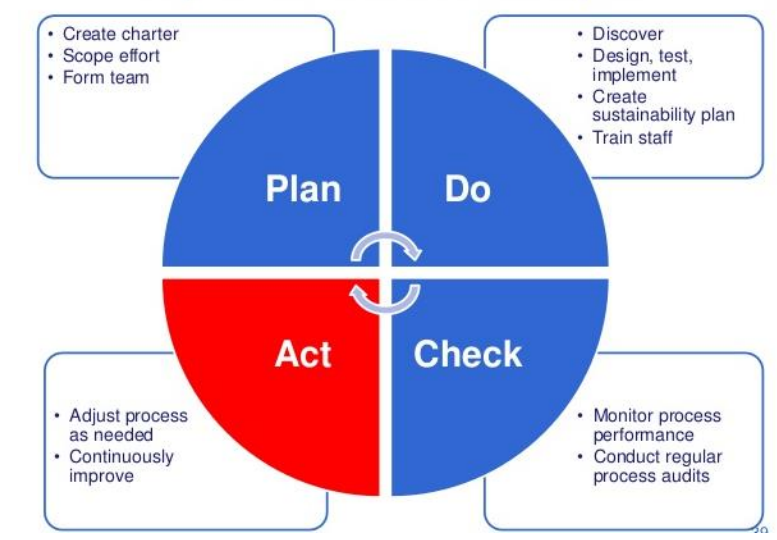

Source: Deming (1993) 
According to Al Ali (2012), Total Quality Management (TQM) has wider approach, including also top management and strategy planning, all stakeholders, like customers, partners, suppliers, competitive organizations, etc. TQM embraces quality management philosophy, together with continuous improvement, customer satisfaction, long-term goals, employee's engagement and work culture, teamwork, process redesign; data based results, flexibility and competitive benchmarking. To summarize, TQM is presented as interdependence of management process including core values, tools and techniques. The target of principles is to achieve constant improvement in quality and productivity (increase of company's effectiveness), as opposed to make changes after the act. These principles guide to the transformation within the company, regardless its size (micro, small, medium or large company, department or team), type of business (product or service manufacturing) or profitability (profit or non-profit). He points out the necessity to be open for changes, which starts from the individuals and through interaction with others, leads to complete transformation and customer satisfaction.

Some TQM principles are recognized to have core values - leadership, everybody's commitment and customer-focus, with importance of process change. Total Quality Management (TQM) is a wider concept than quality control or quality assurance, as it takes into account the whole organization, and not only the product.

TQM is described as long-term customer-focused approach, where all organization members participate in improvement of product or service. TQM uses strategy, data and TQM has already become a standard in the Directorate General of Translation from 2007 (Hansson, 2003). Alhashmi (2016) performed analysis of TQM principles (including quality assurance, quality control and quality verification) on the overall value-chain translation process for English-Arabic. Schiaffino et al. (2013) have developed Translation Quality Index in order to obtain useful information for benchmarking of translations. The main aim was to assess ratio between quality and cost, taking into account linguistic and technical background, detail-oriented editors and knowledgeable proof-readers, terminology work, time aspect and customer feedback.

\section{Results}

The case study is performed on 12 Croatian language and service provider (LSP) companies. The first criteria to analyse was number of employees. As Figure 2 presents, more than $90 \%$ are micro and small companies: $50 \%$ (or 6 companies) are micro companies with < 10 employees (among which 5 of them have 1-5 employees, $41.67 \%$ are small companies having 10-49 employees and only one company having more than 50 employees.

Figure 2

Number of Employees

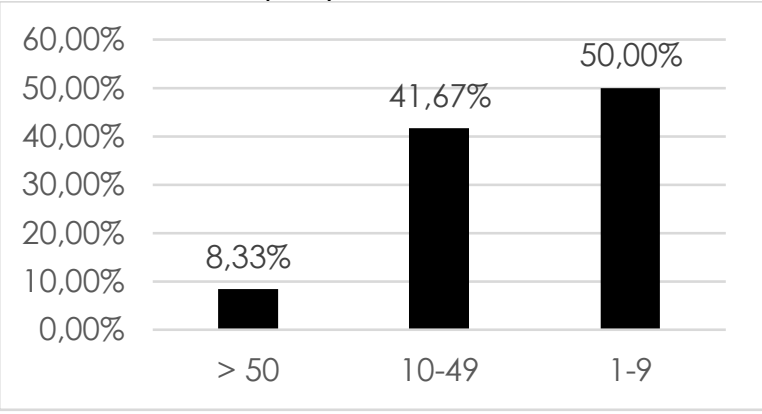

Source: Authors' illustration 
Issue on existing workplaces, shows that in all micro companies the function of the director is run by the owner of the company. In all of them, translator's workplace exists, and $83 \%$ (5 out of 6) micro companies employ the project manager. This results shows that the main task - translation is seen no more as a single task, but as a teamwork, asking for process redesign and flexibility.

Small companies with 10-49 employees have the following workplaces: all small companies employ the financial expert, IT expert in the technical department and staff expert. Companies with more than 20 employees have the workplace for business analytic expert. Issue on missing workplaces shows that in $25 \%$ of companies the marketing / PR workplace is needed and in $25 \%$ of companies the workplace of language engineer and localization expert, which shows the need for interdisciplinary team and collaboration. This workplace analysis shows the need for adaptation in order to base the work on data-driven decision-making.

Figure 3 presents office distribution: $58 \%$ of companies have offices in the capital city of Croatia - 5 micro companies with less than 10 employees and 2 small companies. 2 companies (one micro and one small) have offices in Croatia and in the region, and three small companies and one medium company with more than 50 employees have companies in different EU countries.

Figure 3

Office Distribution

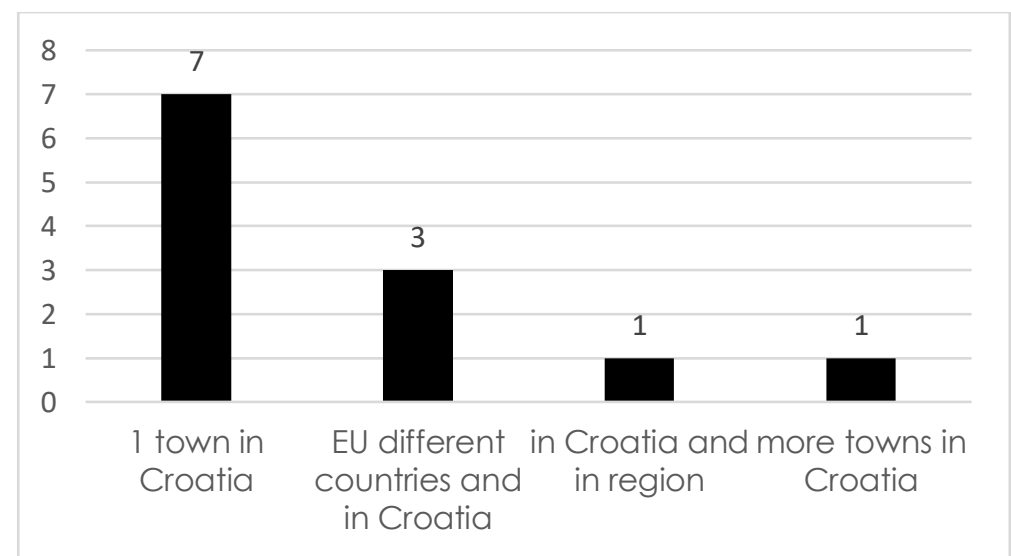

Source: Authors' illustration

Figure 4 presents that more that $41 \%$ of Croatian LSP companies are focused to the world market (one medium company and 4 out of 5 small companies). Two more companies (17\%) are focused to EU market, which makes all together $58 \%$ or $7 / 12$ of companies aiming to offer their services to the global multilingual environment and present themselves at international competitive market. $17 \%$ of companies, i.e. $2 / 12$ companies are oriented to the regional market and $25 \%$ or $3 / 12$ companies to the national market. All companies focused to the world market have offices in different EU countries, regions or in the capital city.

All companies aiming to the world market are members of professional associations, except, interestingly, the medium company. Out of total number, $41 \%$ or 5/6 of LSP Croatian companies (5 out of 6 ) are not members of professional associations ( 4 micro companies and 1 micro company), and $58 \%$ of them with more than 10 employees are members of professional associations. This results show the will to be included into international associations, gain new competences, to network with possible partners and to place themselves at the international market 
Figure 4

Targeted Business Market

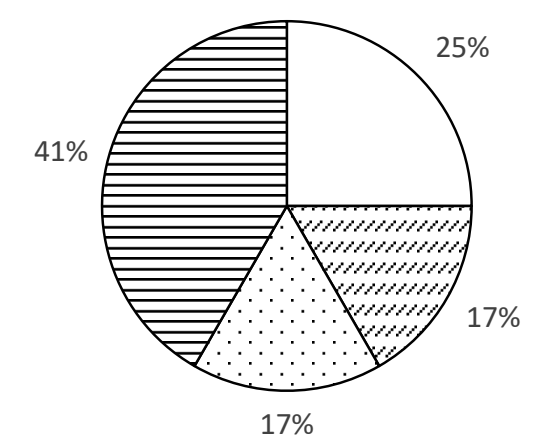

口Croatia

घregion

$\square$ EU countries

घworld marke†

Source: Authors' illustration

Regarding companies' interest for the quality certification, out of total number, only 50\% of companies have obtained The Quality Certificate ISO 9001 and 2 more companies are in the process of obtaining it. $33 \%$ of companies (4/12 companies) have declared that they do not need it. However, all companies aiming to the world market and EU market (except 1 small company) have obtained ISO 9001 quality certificate.

Figure 5

The Quality Certificate ISO 9001

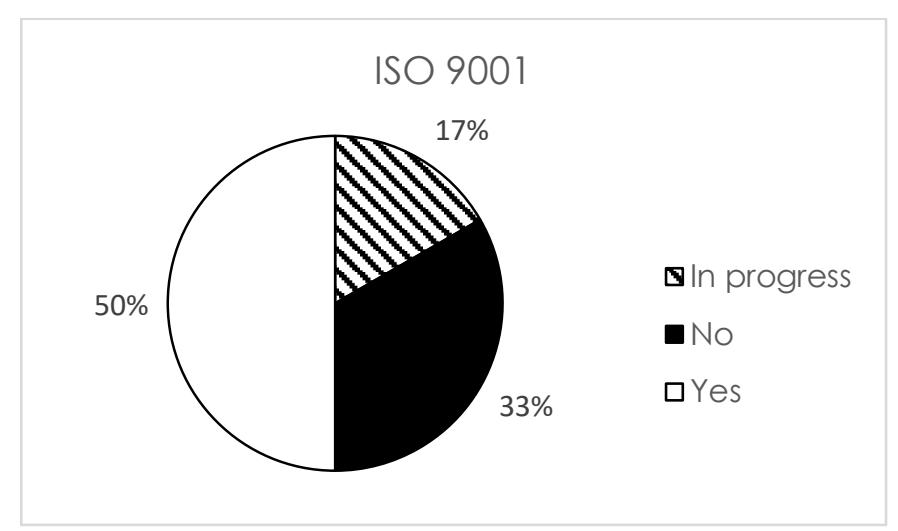

Source: Authors' illustration

According to Weinstein et al. (2009), quality should be clearly stated from the beginning. Applied on LSP companies, quality can relate to product quality, i.e. to quality of the final text output, but also to growth of sales, decreased number of complaints, reduced costs of eliminating errors, shortened time for productions, reducing costs of future work by using innovative methods, faster turnaround, or more satisfied customer in order to assure the quality during the whole process.

In considered Croatian LSP companies, quality control of the final text product is performed in two companies $(16,6 \%)$ by one person (lector/ proof-reader); in three more companies (25\%) also by bilingual reviewer and in $58 \%$ of companies there are three steps of quality control, conducted by three different persons. Quality control is always performed by in-house staff, then by outsourced freelancers or customers. The focus of the review is on text $(84 \%)$, while only $16 \%$ (or 2 companies) use 
additional software (besides software integrated into CAT tools) and keep evidence on error types, error typology, post-editing productivity testing, error severity, terminology consistency, time, etc. None of the considered companies use automatic metrics or some type of dynamic quality framework (DQF) in order to evaluate automatic machine translation outputs and predict possible post-editing efforts.

The 12 Croatian LSP SME companies have performed self-evaluation of the current state of TQM principles. Results show that the lowest attention is given to data based decision making with average grade 4.17 (out of 5), namely in all micro companies, out of which $83 \%$ having up to 5 employees. One medium company, 2 small companies and 2 micro companies have declared to use data based decision making.

The second lowest position is given to leadership (4.25), systematic management (4.25) and continuous improvement (4.25), characteristic for the micro companies. These results show that most of considered LSP companies have not yet adapted to changes in business processes by implementing technology-driven information management. On the other side, the highest scores are given to engagement of people (4.75) and customer-focus (4.67), which shows approach that is more traditional in micro and small companies, where fewer number of people are engaged in several types of jobs and are focused on the small number of customers.

Figure 6

Self-Evaluation of Total Quality Management (TQM) Principles

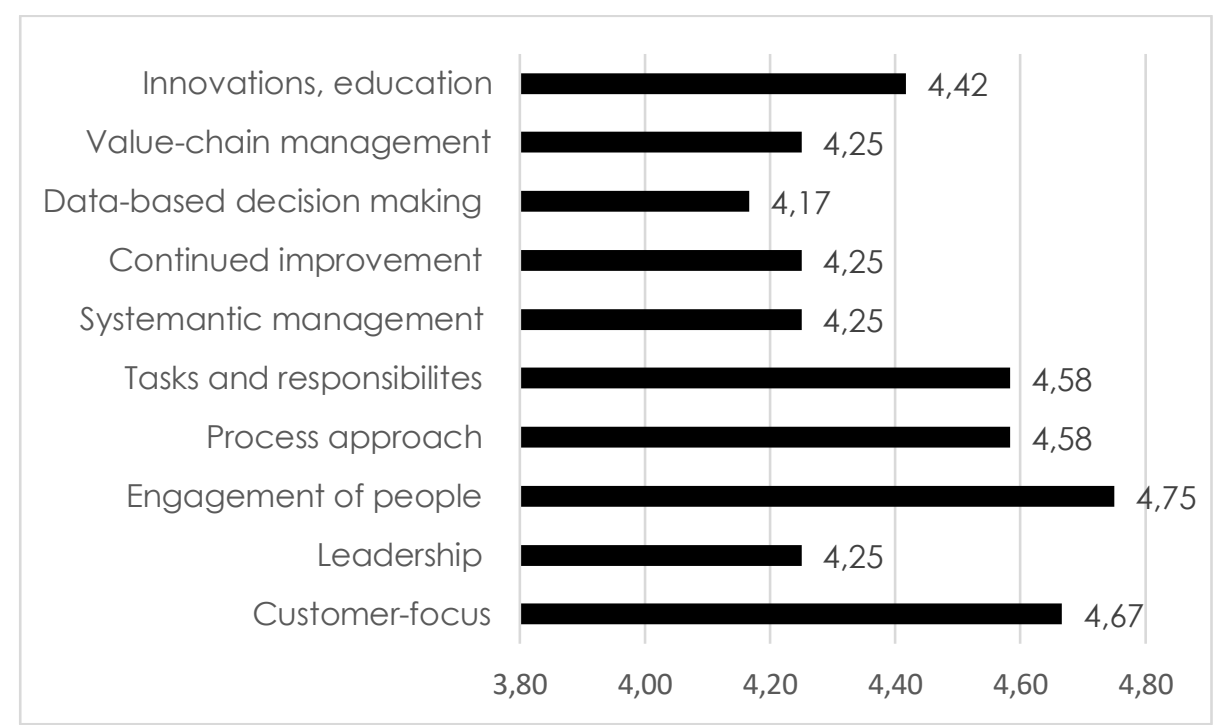

Source: Authors' illustration

\section{Conclusion}

The aim of this paper was to perform analysis of existing practices of Total Quality Management (TQM) principles in Croatian Language Service Provider (LSP) micro, small and medium companies, in order to analyse the gap and suggest recommendations. In this case study, 12 Croatian LSP companies are analysed, by aligning selected TQM principles with existing practice through self-evaluation assessment.

Results of the research show the dominance of micro and small companies with more than 90\% (50\% micro companies and $41.67 \%$ small, employing director (at the same time the owner), translator(s) and project manager. In $25 \%$ of companies, the 
workplace of language engineer/ localization expert and marketing/ PR expert are missing. $58 \%$ of companies (7 out of 12) are focused to the European and world market, showing the need to implement Total Quality Management (TQM) principles. Small companies with 10-49 employees and one with more than 50 employees, employ the financial expert, IT department and staff office. Companies with more than 20 employees, have the workplace for business analytic expert, which shows need for data-driven decision-making. Companies aiming to the world market are members of professional associations. 50\% of companies have obtained ISO 9001 Quality Certificate and 2 more companies are in the process of obtaining it, while $33 \%$ of companies have declared that they do not need it.

The research based on self-evaluation of the current state of TQM principles shows that the lowest attention is given to data-based decision making (4.17), followed by leadership (4.25), systematic management (4.25) and continuous improvement (4.25). These results show the traditional business orientation, characteristic for micro companies who do not implement TQM principles. The highest scores are given to engagement of people (4.75) and customer-focus (4.67), where a few employees are engaged in several types of jobs, being focused on specific customers and the ability to continue the cooperation. Quality control is performed in $41 \%$ of considered companies only by lector or by lector and reviewer. $58 \%$ of companies have three steps of quality control. Quality control is performed by in-house staff and then by outsourced freelancers or customers. The focus of the review is on text (84\%), while only $16 \%$ (or 2 companies) use additional software (besides software integrated into CAT tools). None of the considered companies uses automatic metrics or some type of dynamic quality framework (DQF) in order to evaluate automatic machine translation outputs and predict possible post-editing efforts.

Results of the case study show that for considered LSP companies in Croatia the translation task is seen as a teamwork, asking for process redesign and flexibility. The gap exists in the components of data based decision making, leadership function, systematic management and quality improvement, suggesting that Total Quality Management (TMQ) principles are mainly not implemented, except in partly in 1 small and 1 medium company. Quality Management (QM) exits in the quality control of the product (translated text in any forms) conducted at several levels.

Changes in LSP Croatian companies happen at organizational, production, and management levels, with ICT, workflow complexity, through collaborative environment, through new types of jobs and specializations, in process organization, in data based decision-making, relationship management and customer-focus, asking for planned TQM implementation in order to improve selling power and competitiveness at the focused market..

\section{References}

1. Al Ali, E. A. A. A. S. (2012), "Total Quality Management Implementation: A Study to Critical Success Factors and Continuous Improvement to UAE Organizations", Doctoral Dissertation, The British University in Dubai (BUiD), Dubai.

2. Alhashmi, M. (2016), "Embedding TQM in UAE translation organizations", QScience Connect, available at: http://www.ascience.com/doi/abs/10.5339/connect.2016.tii.3 (10 July 2018)

3. Deming, W. E. (1993), The New Economics, MA, MIT Press, Cambridge.

4. European Union (2003/361), C (2003) 1422, Official Journal L 124, 20/05/2003 P. 0036 0041, available at:

https://eur-lex.europa.eu/legal-content/EN/TXT/? uri=celex:32003H0361

5. European Commission - Directorate European General for Translation (2009), Programme for Quality Management in Translation: 22 Quality Actions, available at: 
http://www.termcoord.eu/wp-content/uploads/2017/07/Programme-for-QualityManagement-in-Translation.pdf (10 July 2018)

6. Gural, S. K., Chemezov, Y. R. (2014), "Analysis of Efficiency of Translation Quality Assurance Tools", Procedia - Social and Behavioral Sciences, Vol 154, pp. 360-363.

7. Hansson, J. (2003), "Total quality management - Aspects of implementation and performance: Investigations with a focus on small organizations", Doctoral dissertation No. 6, Lulea University of Technology.

8. Hoyle, D. (1998), ISO 9000 Quality System Development Handbook - a system engineering approach, Routledge.

9. ISO 9001:2015 (2015), "Quality management systems - Requirements", International Organization for Standardization, Geneva, available at https://www.iso.org/files/live/sites/isoorg/files/archive/pdf/en/iso_9001-2015_how_to_use_it.pdf (10 July 2018)

10. Kučiš, V., Seljan, S., Klasnić, K. (2009), "Evaluation of Electronic Translation Tools Through Quality Parameters", in proceedings of the $2^{\text {nd }}$ International conference "The Future of Information Sciences: INFuture2009 - Digital Resources and Knowledge Sharing", 4-6 November 2009, Zagreb, Croatia, pp. 341-351.

11. Makoushina, J. (2007), "Translation quality assurance tools: current state and future approaches", Translating and the Computer, Vol. 29, pp. 1-39.

12. Seljan, S., Katalinić, J. (2017), "Integrating Localization into a Video Game", in proceedings of the $6^{\text {th }}$ International conference "The Future of Information Sciences: INFuture 2017: Integrating ICT in Society", 8-10 November 2017, Zagreb, Croatia, pp. 43-55.

13. Seljan, S. (in print), "Quality Assurance (QA) of Terminology in a Translation Quality Management System (QMS) in business environment".

14. Seljan, S. (2011), "Translation technology as Challenge in education and business", Informatologia, Vol. 44, No. 4, pp. 279-286.

15. Seljan, S., Pavuna, D. (2006), "Why Machine-Assisted Translation (MAT) Tools for Croatian?", in proceedings of the $28^{\text {th }}$ International Conference on Information Technology Interfaces, 19-22 June 2006, Cavtat/Dubrovnik, Croatia, IEEE, pp. 469-475.

16. Schiaffino, R., Zearo, F. (2013), "Translation quality measurement in practice", 46th ATA Conference, Seattle, available at: http://www.translationquality.com/files/TQM_Proceedings.pdf (10 July 2018)

17. Svoboda, T., Biel, Ł., Łoboda, K. (2017), Quality aspects in institutional translation (Translation and Multilingual Natural Language Processing 8), Language Science Press, Berlin.

18. Weinstein, L., Vourka, R. J., Graman, G. A. (2009), "Costs of quality and maintenance: Improvement approaches", Total Quality Management and Business Excellence, Vol. 20, No. 5, pp. 497-507.

\section{About the author}

Sanja Seljan, Ph. D. is a full professor at the Faculty of Humanities and Social Sciences, University of Zagreb, Department of Information and Communication sciences. Her research interests include language technologies, i.e. machine translation (MT) and CAT tools, localization, natural language processing (NLP), information transfer and communication, educational technologies and data analysis. She has published more than 80 research papers, co-editor of 7 international publications. She was the project manager of the national scientific and research project and two grants, and participated in eight projects (FP7, Tempus, national). She was invited lecturer at 10 European universities, in the European Commission and in the European Parliament. She is a member of different professional associations, member of several international conference and journal review boards. She has been specialising on foreign universities. The author can be contacted at sanja.seljan@ffzg.hr. 